\title{
Epidemiology
}

\section{E Opioid Therapy in the Treatment of Chronic Pain Conditions in Germany}

Andreas Werber, MD', Ursula Marschall, MD², Helmut L'hoest, MD², Winfried Hauser, MD², Babak Moradi, MD', and Marcus Schiltenwolf, MD'

From: ${ }^{2}$ Department of Orthopedics and Trauma Surgery, Heidelberg University Hospital, Heidelberg, Germany; ${ }^{2}$ BARMER Health Insurance Company, Wuppertal, Germany; ${ }^{3}$ Department of Internal Medicine I, Klinikum Saarbrücken, Saarbrücken, Germany and Department of Psychosomatic Medicine, Technische Universität, Munich, Germany

Address Correspondence: Andreas Werber, MD Department of Orthopedics and Trauma Surgery

Heidelberg University Hospital Schlierbacher Landstr. 200a, 69118 Heidelberg, Germany E-mail: andreas.werber@med.uni-heidelberg.de

Disclaimer: A. Werber, U. Marschall, H. L'hoest, B. Moradi, and M. Schiltenwolf have nothing to disclose. W. Häuser reports personal fees from

Pfizer, personal fees from Abbott Germany, personal fees from Daiichi Sankyo, outside the submitted work. Conflict of interest: Each author certifies that he or she, or a member of his or her immediate family, has no commercial association (i.e., consultancies, stock ownership, equity interest, patent/licensing arrangements, etc.) that might pose a conflict of interest in connection with the submitted manuscript.

Manuscript received: 07-30-2014 Revised manuscript received: 10-242014, 02-08-2015 Accepted for publication: 02-10-2015

Free full manuscript: www.painphysicianjournal.com
Background: Primarily used for treating malignant pain, opioids are recently applied for chronic non-tumor pain. For the lack of evidence based strategies from long-term studies, opioids are discussed controversially, esp. considering cost-benefit.

Objectives: The purpose of this study is to evaluate characteristics in prescribing opioids for tumor and non-tumor pain conditions.

\section{Study design: Cost effectiveness study/observational study}

Setting/Methods: Health insurance data of a German statutory health insurance company ( $N=6.800 .000$, data acquisition from 2006 to 2010) was evaluated by assigning opioid prescriptions to certain pain related diagnoses using CART (Classification And Regression Tree) segmentation analysis. Age- and gender-specific characteristics of prescriptions were calculated.

Results: The number of prescriptions of opioid prescriptions increased linearly. Prescriptions of mild opioids were decreasing for non-tumor pain, but increasing for tumor pain, while the number of prescriptions of strong opioids was increasing both for tumor and nontumor pain. Differences occurred in terms of duration and kind of the preferred substances, including the considerations of common contraindications (e.g. somatoform disorders). The majority of strong opioids being prescribed for non-tumor pain were fentanyl pain patches for 40 to 45 year old males with average annual costs of 1833 Euros per patient. Out of 21000 patients with somatoform pain disorder, $44.4 \%$ were treated with opioids $(20.7 \%$ with mild, $23.7 \%$ with strong opioids).

Limitations: The results did not consider if the opioid medication was actually taken by the patients. Another difference in terms of representativeness might occur since the gender distribution varies between the official statistical data and data collected by the health insurance company. Because of the acquisition of the data, no conclusions about possible correlation of pain syndromes and educational and social classes are possible. Tumor patients who received an opioid prescription for non-tumor pain could not be excluded.

Conclusions: While the overall expenditure of the health insurance companies increased, it remains unknown which patient is receiving a particular opioid medication. Prescribing behavior was often not consistent with common indications and contraindications.

Key words: Opioid therapy, chronic pain conditions

Pain Physician 2015; 18:E323-E331 
D) espite the fact that pain treatment is one of the most important problems in general health care, pain is often not treated sufficiently $(1,2)$. Considering the great variety of pain medication and other - more invasive - therapies, the emerging costs, both directly and indirectly, not only burden the budget of the patients, but also of the health insurance system, and therefore, the national economy itself (3).

Some of the most used remedies in pain therapy are opioids for a long time period - and ever since they have been discussed disputedly (4). Originally the dispute was focused on the undersupply, especially for tumor patients (5); opioid medication was also used for treating chronic non-cancer pain (CNCP) (6-8). Even though opioids have been proven effective for treating severe tumor pain syndromes, a pain reduction of more than $50 \%$ is measured only for $25 \%$ of patients with CNCP (9). There is still a lack of evidence of the effectiveness of long-term opioid pain therapy because of missing long-term evaluation data (10).

However, in the clinical treatment of pain conditions, the application of opioid medications both for tumor and non-tumor pain for several years is quite common (11) and the number of prescriptions is increasing (12). Prescribing opioids for CNCP has outpaced the growth of scientific evidence on the benefits and harms of these interventions (13).

In Germany, around $85 \%$ of the population is insured by health insurance companies. The 2 largest companies, AOK (organized regionally in federal states) and BARMER GEK (organized nationwide), cover more than two-thirds of all insured people. By evaluating regularly acquired data from the insurance companies, conclusions from opioid prescribing can be drawn.

The aim of this study was to detect certain characteristics in prescribing behavior in terms of preferential

Table 1. Pain types according to Freytag et al (2010).

\begin{tabular}{|c|c|}
\hline Pain Type & Description of Pain \\
\hline 1 & cancer pain \\
\hline 2 & $\begin{array}{c}\text { other specific lower back pain (including } \\
\text { osteoporosis, excluding diseases of the spinal disc) }\end{array}$ \\
\hline 3 & diseases of the spinal disc \\
\hline 4 & arthrosis \\
\hline 5 & traumatic fractures \\
\hline 6 & people in need of care \\
\hline 7 & neuropathy \\
\hline 8 & headache \\
\hline 9 & unspecific lower back pain \\
\hline
\end{tabular}

treatment for certain groups of patients and favoritism of method of application in Germany using a large dataset evaluated over 5 years (from 2006 to 2010).

\section{Methods}

All data was provided by the compulsory German health insurance company (BARMER GEK). The study is based upon the evaluation of anonymized data of $6,800,000$ insured persons collected from 2006 to 2010 ( $41 \%$ men and $59 \%$ women). The average age was 42.2 years, 40.8 for men and 43.2 for women. These numbers are comparable to the official statistics with $49 \%$ men and $51 \%$ women. The data represent a cross-section of the German population. Race, ethnicity, primary language spoken, marital status, and employment status were not covered by the available insurance data.

For higher reliability and comparability, the data was standardized upon the insured population of a certain year. All patients being prescribed with at least one opioid medication were selected and then further stratified.

Opioids are distinguished in mild substances (type 2, e.g., codeine, hydrocodone, tramadol, tilidine) and strong substances (type 3, e.g., morphine, meperidine, hydromorphone, fentanyl, methadone, oxycodone), according to the proposal by the World Health Organization (WHO) (14). The defined daily dose (DDD) is the assumed average maintenance dose per day for a drug used for its main indication in adults (WHO Collaborating Centre for Drug Statistics Methodology) (15). The DDD is a measurement for the actual prescribed amount of opioid medication rather than the overall number of prescriptions, hence allowing better comparability of opioid consumption.

A period up to 3 weeks of treatment with opioids is considered an acute pain therapy, 3 to 13 weeks of treatment a bridge therapy, and treatment for more than 13 weeks is considered a long-term therapy (16).

The analysis is based upon the number of persons insured by BARMER GEK $(\mathrm{N}=6.8 \cdot 106)$, ordered by age- and gender-specific properties (Ni). To identify patients with pain conditions, it is not sufficient to analyze diagnoses related data, because pain-causing underlying diseases often occur without pain syndromes (17). By using Breiman's CART (Classification and Regression Tree) algorithm (18), particular pain patterns could be classified and integrated into 9 representative morbidity patterns, Table 1 (19), by applying non-parametric decision tree learning to generate a predictive model: the International Statistical 
Opioid Therapy in the Treatment of Chronic Pain Conditions

Table 2. Topmost pain diagnoses treated with mild and strong opioid medication (first quarter of 2010 ).

\begin{tabular}{|c|c|c|c|c|c|c|}
\hline \multirow[b]{2}{*}{ Medication } & \multicolumn{3}{|c|}{ Mild Opioids } & \multicolumn{3}{|c|}{ Strong Opioids } \\
\hline & $\begin{array}{c}\text { no. insured } \\
\text { persons }\end{array}$ & ICD10 code & $\begin{array}{c}\text { Freytag's } \\
\text { morbidity } \\
\text { pattern }\end{array}$ & $\begin{array}{l}\text { no. insured } \\
\text { persons }\end{array}$ & ICD10 code & $\begin{array}{c}\text { Freytag's } \\
\text { morbidity } \\
\text { pattern }\end{array}$ \\
\hline 1 & 52,600 & M54 & 9 & 35,200 & M54 & 9 \\
\hline 2 & 20,800 & M47 & 9 & 29,500 & R52 & $\mathrm{x}$ \\
\hline 3 & 19,200 & M17 & 4 & 18,200 & M81 & 2 \\
\hline 4 & 19,100 & M51 & 3 & 16,200 & M47 & 9 \\
\hline 5 & 18,000 & R52 & $\mathrm{x}$ & 14,700 & M17 & 4 \\
\hline 6 & 15,800 & M81 & 2 & 14,500 & M51 & 3 \\
\hline 7 & 14,300 & M53 & 9 & 10,600 & M16 & 4 \\
\hline 8 & 13,200 & M16 & 4 & 9,800 & M53 & 9 \\
\hline 9 & 9,200 & M79 & 8 & 9,000 & M48 & 2 \\
\hline 10 & 8,900 & M19 & 4 & 7,800 & M79 & 8 \\
\hline 11 & 8,000 & M15 & 4 & 7,300 & M15 & 4 \\
\hline 12 & 7,700 & M48 & 2 & 6,700 & M19 & 4 \\
\hline 13 & 6,800 & G43 & 7 & 6,000 & G62 & 8 \\
\hline 14 & 6,300 & M25 & 4 & 4,900 & $\mathrm{~F} 45$ & $\mathrm{x}$ \\
\hline 15 & 5,000 & G62 & 8 & 4,700 & M06 & 4 \\
\hline
\end{tabular}

1 cancer pain, 2 other specific lower back pain, 3 diseases of the spinal disc, 4 arthrosis, 5 traumatic fractures, 6 people in need of care, 7 neuropathy, 8 headache, 9 unspecific lower back pain, x not classified in Freytag's morbidity patterns

M54: back pain; M47: spondylosis; M17: gonarthrosis; M51: intervertebral disc disorders; R52: pain, not elsewhere classified; M81: osteoporosis without pathological fracture; M53: other dorsopathies, not elsewhere classified; M16: coxarthrosis; M79: other soft tissue disorders, not elsewhere classified; M19: other osteoarthrosis; M15: polyosteoarthrosis; M48: other spondylopathies; G43: migraine; M25: other joint disorder, not elsewhere classified; G62: other polyneuropathies; F45: somatoform disorders; M06: other rheumatoid arthritis

Classification of Diseases and Related Health Problems diagnoses of patients treated with opioids were mapped in several steps to pain morbidity patterns using bivariate analysis, clinical classification software (CCS) grouping, and experts' knowledge. In this case, multimorbidity is defined as 2 or more pain conditions. In decision trees, leaves represent pain morbidity patterns and branches represent conjunctions of features, for example, classification in certain age groups or by differentiating underlying tumor and non-tumor diseases. Splitting rules (based on the specific variable's values) are selected to differentiate observations. These rules are applied recursively until no further segmentation is possible, i.e., generating the leaves of the tree. Depending on the applied decision rules, various, but determined, trees could be generated.

The number of age- and gender-ordered partitions per region (ni) was calculated. The number of occurrences of insured event was calculated, also ordered by age- and gender-specific properties (di). The age- and gender-specific ratio was calculated by $\mathrm{ri}=\mathrm{di} / \mathrm{ni}$. The estimated number of occurrences of insured event, ordered by age and gender, was evaluated by multiplying the age- and gender-specific numbers of insured persons with the corresponding age- and genderspecific ratio $\left(\mathrm{di}^{\prime}=\mathrm{Ni} \cdot \mathrm{ri}\right)$. By summing up all estimated numbers of occurrence of insured event, the number of occurrences of insured events of the whole population could by estimated $\left(d^{\prime}=\Sigma \mathrm{Ni} \cdot \mathrm{ri}\right)$.

\section{RESULTS}

\section{Opioid Prescriptions}

In the first quarter of 2010, the 3 topmost diagnoses being treated with mild opioid medication were back pain $(23.4 \%)$, spondylosis (9.3\%), and gonarthrosis $(8.5 \%)$. Those treated with strong opioids were back pain $(18.0 \%)$, unspecific pain $(15.1 \%)$, and osteoporosis $(9.3 \%)$. The top 15 diagnoses treated both with mild and strong opioid medications are listed in Table 2. All ICD-10 codes, except R52 (pain, not elsewhere classified) and F45 (somatoform disorders), are enclosed in Freytag's morbidity patterns.

In 2006, around 400,000 (5.7\%) patients obtained 
Pain Physician: May/June 2015; 18:E323-E331

Table 3. Number of opioid prescriptions in 2006 and 2009 ordered by duration of application and non-tumor or tumor disease (percentage of insured persons).

\begin{tabular}{|l|c|c|c|c|c|c|c|c||}
\hline \multicolumn{1}{|c|}{ Disease } & \multicolumn{3}{c|}{ Tumor } & \multicolumn{4}{c|}{ Non-Tumor } \\
\hline \multicolumn{1}{|c|}{ Opioid Type } & \multicolumn{2}{|c|}{ II } & \multicolumn{2}{c|}{ III } & \multicolumn{3}{c|}{ II } & \multicolumn{2}{c|}{ III } \\
\hline Duration (Months) & $\leq 3$ & $>3$ & $\leq 3$ & $>3$ & $\leq 3$ & $>3$ & $\leq 3$ & $>3$ \\
\hline 2006 & $0.40 \%$ & $0.24 \%$ & $0.16 \%$ & $0.17 \%$ & $3.05 \%$ & $1.38 \%$ & $0.28 \%$ & $0.47 \%$ \\
\hline 2009 & $0.45 \%$ & $0.28 \%$ & $0.19 \%$ & $0.23 \%$ & $2.78 \%$ & $1.44 \%$ & $0.36 \%$ & $0.65 \%$ \\
\hline
\end{tabular}

Opioid type: II mild opioids (codeine, hydrocodone, tramadol, tilidine), III strong opioids (morphine, oxycodone, meperidine, hydromorphone, fentanyl, methadone).

at least one prescription of opioid medication, independent of the underlying disease. This fraction increased to $5.9 \%$ in $2009(+3.5 \%)$. The portion of patients who could be assigned to a pain morbidity pattern without opioid prescription remained constant at $34 \%$.

By distinguishing the number of opioid prescriptions in terms of tumor and non-tumor disease, the number of mild opioids decreased for non-tumor diseases from $4.44 \%$ in 2006 to $4.21 \%$ in $2009(-5.2 \%)$. In contrast to this, the number of mild opioids increased for tumor diseases from $0.64 \%$ in 2006 to $0.73 \%$ in 2009 $(+14.1 \%)$. The number of prescriptions for strong opioids was increasing both for non-tumor (2006: 0.75\%, 2009: $1.01 \%,+34.7 \%$ ) and tumor diseases (2006: $0.33 \%$, 2009: $0.42 \%,+27.3 \%)$. The increase of prescriptions both for mild and strong opioids was virtually linear.

By differentiating between the number of opioid prescriptions and the duration of application and tumor or non-tumor disease, the number of prescriptions increased nearly straight proportional both for shortterm and long-term application and both for mild and strong opioids except for short-term application of mild opioids for non-tumor diseases, where the number decreased from $3.1 \%$ in 2006 to $2.8 \%$ in $2009(-8.9 \%)$ (Table 3).

\section{Defined Daily Dos}

For tumor pain, the DDD of opioids increased for mild opioids from 3,025,000 in 2006 to $3,718,000$ in $2009(+22.9 \%)$ and for strong opioids from 3,257,000 to $4,369,000$ in $2009(+34.1 \%)$. For non-tumor pain, the DDD of opioids increased virtually linearly for mild opioids from 18,035,000 in 2006 to $19,744,000$ in $2009(+9.5 \%)$ and for strong opioids from $9,363,000$ to $12,647,000$ in $2009(+35.1 \%)$.

\section{Morbidity Pattern}

For all patients with exactly one pain condition, more mild than strong opioids were prescribed. First, patients who were assigned to exactly one of Freytag's morbidity patterns were surveyed: $1.5 \%$ of patients with a tumor disease (pattern 1) were treated with mild opioids and $2.4 \%$ were treated with strong opioids. Two percent of all patients with unspecific lower back pain (pattern 9) were treated with mild opioids and $0.3 \%$ with strong opioids. Merely for tumor pain, more strong than mild opioids were prescribed. Most patients treated with opioids were assigned to Freytag's people in need of care pattern (co-occurrence of 2 or more chronic medical conditions, i.e., multimorbidity, with need of assistance in activities of daily living) (pattern 6): $2.7 \%$ were treated with mild and $2.4 \%$ were treated with strong opioid medication (Table 4).

Out of all patients who were assigned to multimorbidity patterns, e.g., 2 or more pain conditions, $9.8 \%$ of patients with a tumor diagnosis (pattern 1) as leading disease pattern were treated with mild and $10.6 \%$ were treated with strong opioids. Because of the consideration of multiple pain conditions, the number of prescriptions of mild opioids increased by a factor of 6.4, e.g., for patients with 2 or more pain conditions, 6.4 times more opioids were prescribed compared to those with only one pain condition. For strong opioids the number of prescriptions increased by a factor of 4.57 compared to patients without multiple pain conditions.

Thirteen point two percent of all patients with unspecific lower back pain (pattern 9) as the leading symptom of multimorbidity were treated with mild opioids and $4.8 \%$ with strong opioids which equates to an increase for mild opioids prescriptions by a factor of 13.6 and for strong opioids by a factor of 21 .

The greatest portion was patients who were assigned to Freytag's people in need of care morbidity pattern (pattern 6) as the leading symptom: $19.2 \%$ were treated with mild and $18.6 \%$ were treated with strong opioid medication. The number of mild opioid prescriptions increased by a factor of 7.0 and for strong opioids by a factor of 7.7.

For spinal disc diseases (pattern 3) as the leading disease pattern, the factor increased to 24.8 for mild 
Table 4. Number of insured persons treated with opioids ordered by opioid type and number of pain types according to Freytag et al (2010) (percentage of insured persons).

\begin{tabular}{|c|c|c|c|c|c|c|}
\hline \multirow[t]{2}{*}{ Pain Type } & \multicolumn{2}{|c|}{$\begin{array}{c}\text { Number of Morbidity Patterns } \\
\text { Opioid Type II }\end{array}$} & \multirow[t]{2}{*}{$\Delta$} & \multicolumn{2}{|c|}{$\begin{array}{c}\text { Number of Morbidity Patterns } \\
\text { Opioid Type III }\end{array}$} & \multirow[t]{2}{*}{$\Delta$} \\
\hline & 1 & 2 Or More & & 1 & 2 Or More & \\
\hline 1 & $1.53 \%$ & $9.8 \%$ & x 6.4 & $2.38 \%$ & $10.6 \%$ & $\times 4.5$ \\
\hline 2 & $0.79 \%$ & $16.2 \%$ & x 20.5 & $0.56 \%$ & $11.4 \%$ & $\mathrm{x} 20.4$ \\
\hline 3 & $0.62 \%$ & $15.4 \%$ & x 24.8 & $0.15 \%$ & $7.0 \%$ & $\mathrm{x} 46.7$ \\
\hline 4 & $1.56 \%$ & $14.0 \%$ & x 9.0 & $0.41 \%$ & $5.8 \%$ & x 14.1 \\
\hline 5 & $1.53 \%$ & $15.6 \%$ & x 10.2 & $0.47 \%$ & $10.4 \%$ & x 22.1 \\
\hline 6 & $2.74 \%$ & $19.2 \%$ & $\mathrm{x} 7.0$ & $2.41 \%$ & $18.6 \%$ & x 7.7 \\
\hline 7 & $1.62 \%$ & $10.8 \%$ & $\mathrm{x} 6.7$ & $0.09 \%$ & $2.8 \%$ & $\mathrm{x} 31.1$ \\
\hline 8 & $1.18 \%$ & $16.0 \%$ & x 13.6 & $0.35 \%$ & $7.6 \%$ & $\mathrm{x} 21.7$ \\
\hline 9 & $2.03 \%$ & $13.2 \%$ & $\mathrm{x} 6.5$ & $0.29 \%$ & $4.8 \%$ & x 16.6 \\
\hline
\end{tabular}

1 cancer pain, 2 other specific lower back pain, 3 diseases of the spinal disc, 4 arthrosis, 5 traumatic fractures, 6 people in need of care, 7 neuropathy, 8 headache, 9 unspecific lower back pain.

Opioid type: II mild opioids (codeine, hydrocodone, tramadol, tilidine), III strong opioids (morphine, oxycodone, meperidine, hydromorphone, fentanyl, methadone).

opioids (from $0.62 \%$ to $15.4 \%$ ) respectively, to 46.7 for strong opioids (from $0.15 \%$ to $7.0 \%$ ), and for headache (pattern 8), the factor increased to 13.6 for mild opioids (from $1.18 \%$ to $16.0 \%$ ) respectively, to 21.7 for strong opioids (from $0.35 \%$ to $7.6 \%$ ).

Similar to the findings above, more mild than strong opioids were prescribed for patients with 2 or more pain conditions, except for tumor pain. The ratio was nearly balanced for tumor pain as the leading disease pattern (pattern 1; mild opioids: $9.8 \%$, strong opioids: $10.6 \%$, ratio: 0.92 ) and people in need of care (pattern 6; mild opioids: $19.2 \%$, strong opioids: $18.6 \%$, ratio: 1.03 ) compared to spinal disc diseases (pattern 3; mild opioids: $16.2 \%$, strong opioids: $11.4 \%$, ratio: 1.42 ) and headache (pattern 8; mild opioids: $15.9 \%$, strong opioids: $7.5 \%$, ratio: 2.1 ).

\section{Mental Comorbidities}

Sixteen percent of all insured persons ( 1.07 million) who could be assigned to a morbidity pattern showed a mental comorbidity (depression, anxiety disorder). On the other hand, 320,000 insured persons with a mental disorder could not be assigned to a morbidity pattern, but $1.3 \%$ of them were treated with mild and $0.4 \%$ of them were treated with strong opioids. Out of 21,000 patients with chronic pain syndrome and somatoform pain disorder, $44.4 \%$ were treated with opioids ( $20.7 \%$ with mild, $23.7 \%$ with strong opioids). Except for Freytag's tumor (pattern 1) and multimorbidity (in need of care) morbidity pattern (pattern 6), significantly more mild than strong opioids were pre- scribed. The ratio of mild compared to strong opioids was for tumor pain (pattern 1) 1.1 (mild opioids: $7.1 \%$, strong opioids: $6.5 \%$ ) and for multimorbidity (in need of care) morbidity pattern (pattern 6) 1.0 (mild opioids: $10.5 \%$, strong opioids: $10.3 \%$ ). In contrast, for spinal disc diseases (pattern 3 ) the ratio was 1.9 (mild opioids: 9.8\%, strong opioids: $5.2 \%$ ), for headache (pattern 8 ) 0.9 (mild opioids: $7.4 \%$, strong opioids: $8.3 \%$ ), and for unspecific lower back pain (pattern 9) 2.1 (mild opioids: $7.1 \%$, strong opioids: $3.4 \%$ ).

\section{Medical Specializations}

Out of all insured persons, $22 \%$ were diagnosed with the ICD-Diagnosis R52 (pain, not elsewhere classified), in most cases by general practitioners, who prescribed in $72 \%$ of the cases mild opioids and in $65 \%$ strong opioids, according to a nearly balanced ratio of 1.1. In contrast to this, pain specialists prescribed for the diagnosis R52 3\% mild opioid and $20 \%$ strong opioid medication, resulting in a ratio of 0.15 .

Another diagnosis, F45.41 (persistent somatoform pain disorder with somatic and psychiatric factors) was diagnosed in most cases by pain specialists. In Germany, this diagnosis is a sub-classification of the F45.4 (persistent somatoform pain disorder) (20). In $53 \%$ of the cases mild opioids and in $62 \%$ of the cases strong opioids were prescribed by pain specialists, according to a nearly balanced ratio of 0.85 . By contrast, $27 \%$ of the general practitioners prescribed mild and $24 \%$ strong opioids, resulting in an even more balanced ratio of 1.1 . 


\section{Costs}

In 2010, the overall costs for opioid medication were 1.120 billion Euros, extrapolated for all German health insurance companies, of which $72 \%$ were spent on strong opioids. The 3 topmost expenditures were for fentanyl (mostly spent on pain patches, $25 \%$ ), hydromorphone (14\%), and oxycodone (12\%). Six percent of the costs were spent on morphine. The topmost expenditures for mild opioids were spent on tilidine $(11 \%)$ and tramadol ( $7 \%$, summing up to $14 \%$ including combinations of tramadol).

Note: Tilidine is a mild synthetic opioid, used mainly in Germany, Switzerland, South Africa, and Belgium. In Germany, tilidine is available in a fixed combination with naloxone for oral administration. The mixture of naloxone is claimed to lower the abuse liability of the opioid analgesic. If taken orally, naloxone has minimal effects but if taken intravenously in an abusive manner, naloxone becomes bioavailable and hence antagonizes the effects of the tilidine producing withdrawal effects.

Between 2006 and 2009, the average annual costs were 67 Euros for mild and around 1483 Euros for strong opioid medications. The expenditure on strong opioids is around 22 times the expenditure on mild opioids.

For strong opioids, the average daily costs were 5.92 Euros with a total number of $142,800,000$ DDDs in 2009. For mild opioids, the costs summed up to 1.20 Euro per day with a total number of 215,300,000 DDDs. By comparing the average annual costs for fentanyl and morphine for non-tumor pain, most costs occurred for fentanyl patches for $40-45$ year old men (Fig. 1). The average annual costs for morphine were 933 Euros for men and 733 Euros for women compared to 1833 Euros for fentanyl for men and 1167 Euros for women, according to a ratio of 0.5 for men and 0.6 for women. In contrast, prescriptions for opioid medication for patients with a tumor disease were significantly less age-related. The average annual costs for all opioids were 1559 Euros for men and 1105 Euros for women.

\section{Discussion}

This study surveyed the nationwide acquired data of a compulsory health insurance company in terms of characteristics in prescribing opioid medication in pharmacological pain therapy both for tumor and non-tumor pain in Germany under real conditions. We found an increasing number of opioid prescriptions, both for mild and strong opioids. Around one-third of all opioid prescriptions were issued for back-related pain.

The peak age of opioid usage was $40-45$ years for men and 45 - 50 years for women. The increase in opioid intake cannot be explained merely by the increase of pain and affliction due to physical wear out. We assume that the intersection of the peak of occupational demands and the beginning of physical wear out yields a decrease in physical capacity, hence causing an increase of pain load, not least by the increase of personal stress level.

By using regional random samples from a regional German compulsory health insurance company (AOK Hessen), collected from 2000 to 2010 , Schubert et al (1) showed an increasing number of opioid prescriptions from $3.31 \%$ to $4.53 \%(+37 \%)$. The prevalence was lower compared to our data (2006: 5.7\%, 2009: 5.9\%), since usage of codeine was excluded in their survey. Our survey confirmed the prior findings in terms of increasing number of prescriptions, increasing number of DDDs, and increasing number of strong opioid prescriptions for CNCP compared to mild opioids. In $2010,70 \%$ of all opioid prescriptions were for nontumor pain syndromes. The increasing number of DDDs $(+109 \%)$ referred for the main part to the increasing number of DDDs per patient $(+53.4 \%)$ and secondly to the increasing number of patients $(+37 \%)$. For tumor patients, the ratio of mild and strong opioid prescriptions remained nearly constant with $50 \%$ in each case, while for patients with $\mathrm{CNCP}$, the number of prescriptions for mild opioids decreased from $84 \%$ in 2000 to $66 \%$ in $2010(-27.3 \%)$, but the number of strong opioids increased from $16 \%$ in 2000 to $33 \%$ in 2010 (+106.3\%). However, because the data acquisition showed regional characteristics in morbidity and treatment behavior, only limited comparability is possible to our nationwide evaluated data. Furthermore, in contrast to our survey, Schubert et al's study (1) did not touch the diagnoses related to pain medication, psychiatric comorbidity, or the correlation of pain and multimorbidity. Hence, there was no further exploration of the prescription details.

In a recent study in Norway from Fredheim et al (21), a $9 \%$ increase was observed in the number of persons receiving opioids from 2004 to 2007.

Originally the dispute over the proper indications for opioid therapy was focused on the undersupply, especially in tumor patients (5). Later, the focus was altered since opioids were also used for treating CNCP $(6,7)$. In Germany, a medical guideline for long-term application of opioids for treating non-tumor pain (LONTS) was published in 2009 (16). The results are based on surveys comparing the effectiveness of differ- 
ent types of pain medication, especially non-steroidal anti-inflammatory drugs (NSAIDs) and opioids. One main issue was that opioids are effective on neuropathic pain, lower back pain, and arthralgia, leading to a better functionality and quality of sleep, but not to a better quality of life. However, the pain relief from NSAIDs was comparable to that of opioids. Over time, the pain relief of opioids even diminished. Therefore, in terms quality of life, long-term application of opioids yields no advantage compared to NSAIDs. Critics claim that the guideline is merely a meta-analysis of a few studies about the treatment of women with osteoarthritis or neuropathic pain with morphine and oxycodone for 3 to 13 weeks. Based on the United States Preventive Services Task Force (USPSTF) criteria, Manchikanti et al (22) evaluated the indicated level of evidence, which was fair for tramadol in managing osteoarthritis. For all the drugs assessed, including tramadol, for all other conditions, the evidence was poor based on either weak positive evidence, indeterminate evidence, or negative evidence $(8,22)$. Kahan et al $(23)$ conducted a comprehensive review of the current literature for randomized controlled trials (RCTs) of opioids for cancer pain emphasizing the paucity of long-term trials.

Our detection of increasing numbers both in dosage and duration of opioid therapies poses the question if dangers of addiction have an influence upon the number of prescriptions. Logan et al (24) showed that high daily doses and long-acting/extended-release opioids are indicators for misuse. Hence, it is most likely that physical and/or psychological addiction leads to inappropriate prescribing and misuse of opioids.

Furthermore, we found an exceptionally increasing number of opioid prescriptions in correlation with psychiatric comorbidity. In this context, psychiatric comorbidities yield a great influence on the drug intake behavior of the patients. Breivik (25) proved that the outlook for successful long-term opioid therapy is better in a patient with a stable psychosocial situation than a patient from a complex and unstable psychosocial background. According to the guideline for longterm application of opioids for treating LONTS, opioid medication should be avoided for pain which depends on the prevailing psychological state of the patient. Furthermore, opioids should be avoided for treating primary headache, pain syndromes which occur intermittently with pain-free intervals, and for somatoform disorders. (Since 2009, a specific ICD-10 code for chronic pain disorders was established in Germany, emphasizing psychiatric factors as an important parameter in the process of chronification (26). Characteristics are pain symptoms for at least 6 months in one or more anatomic locations, originally associated with a physical or physiological dysfunction. Psychological factors yield an influence upon severity, exacerbation, or continuance of the pain syndromes; however, these factors are not the cause of the disorder.)

Mental comorbidities yield a great influence upon the perception of pain syndromes. Since the strength of pain is not measurable in a repetitious accurate scale and objectively verifiable, the perception of pain is always a subjective value. If the (objective) clinical, laboratory, and radiological tests revealed no pathological findings to explain the (subjective) ailments, other parameters, such as mental pressure or biographical factors, must be taken into consideration to explain the increased pain perception. Despite common recommendations of avoiding opioid medication on psychiatric impaired patients, $44.4 \%$ of patients with a mental disorder were treated with opioid medication with a nearly balanced ratio of mild and strong opioids.

Noticeable was the number of opioid prescriptions for headache and unspecific lower back pain. Out of all patients with headache, $15.9 \%$ were treated with mild and $7.5 \%$ were treated with strong opioids. Thirteen point one percent of patients with unspecific lower back pain were prescribed mild opioids and $4.8 \%$ were prescribed strong opioids. Especially noticeable was the number of opioid prescriptions for multimorbidity. Around $20 \%$ of all patients were treated with opioid medication in equal parts with mild and strong opioids.

The overall expenditure of all German health insurance companies was 175.6 billion Euros in 2009. Around 32.4 billion Euros (18.5\%) of the expenditure was spent on drugs (including pain medication). The overall cost for opioid medication was more than 1.08 billion Euros (extrapolated for all health insurance companies in Germany). Hence more than 3\% of all costs were spent on opioid medication, in most cases on fentanyl. These results were confirmed by surveys in other nations. In Israel, the number of opioid prescriptions for 5 strong opioids increased by $47 \%$, from 2.46 DDD/1,000 inhabitants per day in 2000 to 3.61 DDD/1,000 inhabitants per day in 2008 (27). This rise was mainly the result of a 4-fold increase in fentanyl consumption from $0.32 \mathrm{DDD} / 1,000$ inhabitants per day in 2000 to $1.28 \mathrm{DDD} / 1,000$ inhabitants per day in 2008, while the number of morphine DDD was decreasing by 50. In Spain, since 1992, the overall opioid consumption has increased 14-fold, from 0.3 DDD/1000 inhabitants 
per day to $4.4 \mathrm{DDD} / 1000$ inhabitants per day (28). For 6 strong opioids, the consumption increased from 0.1 DDD/1000 inhabitants per day in 1992 to 1.2 in 2006. During this same period, the total costs of these prescriptions increased by 36.8 -fold, and the cost per day and per patient doubled.

In a survey by Pflughaupt et al in 2010 (29), incomplete knowledge of physicians was detected considering indication, principles of therapy, pharmacological aspects, and legal ordinance of narcotic analgesic substances. Many physicians would prescribe strong opioids for non-opioid-sensitive types of pain. Addiction and rare adverse reactions were considered relevant in medical practice and more important than legal ordinance. Therefore it is remarkable that $22 \%$ of all insured patients were diagnosed with unspecific pain syndromes and treated by general practitioners in $72 \%$ of the cases with mild opioids and in $65 \%$ with strong opioids in a nearly balanced ratio. In the same case, pain specialists prescribed $3 \%$ mild opioid and $20 \%$ strong opioid medication, hence 6.6 times more strong opioids compared to mild opioids.

Noticeable is the broad use of fentanyl pain patches causing enormous costs to health insurance companies. In Germany, transdermal application of fentanyl as first line treatment is only indicated for patients with dysphagia or massive emesis $(30,31)$.

\section{Strengths and limitations}

Since the difference between billing procedures in distinct insurance companies is negligible, there is virtually no observer or selection bias within this study. Therefore it was possible to analyze age- and gender-specific diagnoses and therapies over duration of several years.

The results did not consider if the opioid medication was actually taken by the patients. Another difference in terms of representativeness might occur since the gender distribution varies between the official statistical data and data collected by the health insurance company. Because of the acquisition of the data, no conclusions about possible correlation of pain syndromes and educational and social classes are possible. Around $80 \%$ of the German population is insured by compulsory health insurance companies; hence, our finding might be different from that of private insurance companies. Furthermore, we could not identify tumor patients who received an opioid prescription for non-tumor pain.

\section{Conclusions}

Opioids are essential in pharmacological pain therapy. The widespread use of opioids is still in contrast to available surveys. This survey showed that opioids are broadly used in pharmacological pain therapy, even for treating symptoms for which opioid medication is not recommended or is even contraindicated, leading to misapplication and addiction.

Most opioids are used for non-tumor pain. Therefore, the increasing number of prescriptions of opioids is not necessarily linked with a better patient care both for tumor and non-tumor pain.

Samples from health insurance companies provide the possibility of long-term evaluation of pharmacological pain therapy. Especially economic aspects of pharmacological pain therapy can be evaluated leading to a better distribution of available funds.

\section{References}

1. Schubert I, Ihle P, Sabatowski R. Increase in opiate prescription in Germany between 2000 and 2010: A study based on insurance data. Dtsch Arztebl Int 2013; 110:45-51.

2. Zenz M, Zenz T, Tryba M, Strumpf M. Severe undertreatment of cancer pain: $A$ 3-year survey of the German situation. J Pain Symptom Manage 1995; 10:187-191.

3. Robert-Koch-Institut. Chronische Schmerzen (Chronic Pain Disorder). Berlin, 2002. RKI, Berlin.

4. Ho KY, Chua NH, George JM, Yeo SN, Main NB, Choo CY, Tan JW, Tan KH, Ng BY. Evidence-based guidelines on the use of opioids in chronic non-cancer pain - a consensus statement by the Pain Association of Singapore Task Force. Ann Acad Med Singapore 2013; 42:138-152.

5. Koyyalagunta D, Bruera E, Solanki DR, Nouri KH, Burton AW, Toro MP, Bruel BM, Manchikanti L. A systematic review of randomized trials on the effectiveness of opioids for cancer pain. Pain Physician 2012; 15:ES39-ES58.

6. Manchikanti L, Abdi S, Atluri S, Balog CC, Benyamin RM, Boswell MV, Brown KR, Bruel BM, Bryce DA, Burks PA, Burton AW, Calodney AK, Caraway DL, Cash KA, Christo PJ, Damron KS, Datta S, Deer TR, Diwan S, Eriator I, Falco FJ, Fellows B, Geffert S, Gharibo CG, Glaser SE,
Grider JS, Hameed H, Hameed M, Hansen $\mathrm{H}$, Harned ME, Hayek SM, Helm S, 2nd, Hirsch JA, Janata JW, Kaye AD, Kaye AM, Kloth DS, Koyyalagunta D, Lee $M$, Malla Y, Manchikanti KN, McManus CD, Pampati V, Parr AT, Pasupuleti R, Patel VB, Sehgal N, Silverman SM, Singh V, Smith HS, Snook LT, Solanki DR, Tracy $\mathrm{DH}$, Vallejo R, Wargo BW. American Society of Interventional Pain Physicians (ASIPP) guidelines for responsible opioid prescribing in chronic non-cancer pain: Part I - evidence assessment. Pain Physician 2012; 15:S1-S65.

7. Manchikanti L, Abdi S, Atluri S, Balog CC, Benyamin RM, Boswell MV, Brown 
KR, Bruel BM, Bryce DA, Burks PA, Burton AW, Calodney AK, Caraway DL, Cash KA, Christo PJ, Damron KS, Datta S, Deer TR, Diwan S, Eriator I, Falco FJ, Fellows B, Geffert S, Gharibo CG, Glaser SE, Grider JS, Hameed H, Hameed $M$, Hansen $H$, Harned ME, Hayek SM, Helm S, 2nd, Hirsch JA, Janata JW, Kaye AD, Kaye AM, Kloth DS, Koyyalagunta D, Lee M, Malla Y, Manchikanti KN, McManus CD, Pampati $V$, Parr AT, Pasupuleti $R$, Patel VB, Sehgal N, Silverman SM, Singh V, Smith HS, Snook LT, Solanki DR, Tracy DH, Vallejo R, Wargo BW. American Society of Interventional Pain Physicians (ASIPP) guidelines for responsible opioid prescribing in chronic non-cancer pain: Part 2 - guidance. Pain Physician 2012; 15:S67-S116.

8. Manchikanti L, Vallejo R, Manchikanti KN, Benyamin RM, Datta S, Christo PJ. Effectiveness of long-term opioid therapy for chronic non-cancer pain. Pain Physician 2011; 14:E133-E156.

9. Sorgatz $H$, Hege-Scheuing $G$, Kopf $A$, Maier C, Sabatowski R, Schafer M, Stein C, Tolle TR, Willweber-Strumpf A. [Consensus building on "Long-term opioid administration and non-tumor pain"]. Z Arztl Fortbild Qualitatssich 2002; 96:317-323.

10. Martell BA, O'Connor PG, Kerns RD, Becker WC, Morales KH, Kosten TR, Fiellin DA. Systematic review: opioid treatment for chronic back pain: Prevalence, efficacy, and association with addiction. Ann Intern Med 2007; 146:116-127.

11. Ashworth J, Green DJ, Dunn KM, Jordan KP. Opioid use among low back pain patients in primary care: Is opioid prescription associated with disability at 6-month follow-up? Pain 2013; 154:1038-1044.

12. Schwarzer A, Maier C. [Opiates in the treatment of non-cancer-related pain]. MMW Fortschr Med 2011; 153:51-53.

13. Chapman CR, Lipschitz DL, Angst MS, Chou R, Denisco RC, Donaldson GW, Fine PG, Foley KM, Gallagher RM, Gil- son AM, Haddox JD, Horn SD, Inturrisi CE, Jick SS, Lipman AG, Loeser JD, Noble M, Porter L, Rowbotham MC, Schoelles KM, Turk DC, Volinn E, Von Korff MR, Webster LR, Weisner CM. Opioid pharmacotherapy for chronic non-cancer pain in the United States: A research guideline for developing an evidence-base. J Pain 2010; 11:807-829.

14. WHO. Cancer Pain Relief. World Health Organization Publications, Geneva, 1986.

15. WHOCC. DDD Definition and general considerations, in CCfDSM (ed). www.whocc.no/ddd/ definition_and_general_considera/.

16. Reinecke $\mathrm{H}$, Sorgatz $\mathrm{H}$. [ $\mathrm{S}_{3}$ guideline LONTS. Long-term administration of opioids for non-tumor pain]. Schmerz 2009; 23:440-447.

17. Lindena G, Hildebrandt J, Diener HC, Schops P, Maier C. [Pain treatment facilities in Germany. Ambulatory, day care and inpatient facilities for patients with chronic pain]. Schmerz 2004; 18:10-16.

18. Breiman L. CART: Classification and Regression Trees. Crc Pr Inc., 1984.

19. Freytag A, Schiffhorst G, Thoma R, Strick K, Gries C, Becker A, Treede RD, MullerSchwefe G, Casser HR, Luley C, Hoer A, Ujeyl M, Gothe H, Kugler J, Glaeske G, Haussler B. [Identification and grouping of pain patients according to claims data]. Schmerz 2010; 24:12-22.

20. Nilges P, Rief W. [F45.41: Chronic pain disorder with somatic and psychological factors: A coding aid]. Schmerz 2010; 24:209-212.

21. Fredheim OM, Skurtveit $\mathrm{S}$, Breivik $\mathrm{H}$, Borchgrevink PC. Increasing use of opioids from 2004 to 2007 - pharmacoepidemiological data from a complete national prescription database in Norway. Eur J Pain 2010; 14:289-294.

22. Manchikanti L, Ailinani $\mathrm{H}$, Koyyalagunta D, Datta S, Singh V, Eriator I, Sehgal N, Shah R, Benyamin R, Vallejo R, Fellows B, Christo PJ. A systematic review of randomized trials of long-term opioid management for chronic non-cancer pain. Pain Physician 2011; 14:91-121.

23. Kahan M, Mailis-Gagnon A, Tunks E. Canadian guideline for safe and effective use of opioids for chronic noncancer pain: Implications for pain physicians. Pain Res Manag 2011; 16:157-158.

24. Logan J, Liu Y, Paulozzi L, Zhang K, Jones $C$. Opioid prescribing in emergency departments: The prevalence of potentially inappropriate prescribing and misuse. Med Care 2013; 51:646-653.

25. Breivik $\mathrm{H}$. Opioids in chronic non-cancer pain, indications and controversies. Eur J Pain 2005; 9:127-130.

26. Rief W, Zenz M, Schweiger U, Ruddel $\mathrm{H}$, Henningsen $\mathrm{P}$, Nilges P. Redefining (somatoform) pain disorder in ICD-10: A compromise of different interest groups in Germany. Curr Opin Psychiatry 2008; 21:178-181.

27. Ponizovsky AM, Marom E, Zeldin A, Cherny NI. Trends in opioid analgesics consumption, Israel, 2000-2008. Eur ] Clin Pharmacol 2011; 67:165-168.

28. Garcia del Pozo J, Carvajal A, Viloria JM, Velasco A, Garcia del Pozo V. Trends in the consumption of opioid analgesics in Spain. Higher increases as fentanyl replaces morphine. Eur J Clin Pharmacol 2008; 64:411-415.

29. Pflughaupt $M$, Scharnagel $R$, Gossrau G, Kaiser U, Koch T, Sabatowski R. [Physicians' knowledge and attitudes concerning the use of opioids in the treatment of chronic cancer and non-cancer pain]. Schmerz 2010; 24:267-275.

30. AkdÄ. Die unkritische Anwendung von Fentanylpflastern erhöht das Risiko für schwerwiegende Nebenwirkungen. Dtsch Arztebl 2012; 109.

31. Radbruch L, Sabatowski R, Petzke F, Brunsch-Radbruch A, Grond S, Lehmann KA. Transdermal fentanyl for the management of cancer pain: A survey of 1005 patients. Palliat Med 2001; 15:309-321. 
